\title{
Short-term dynamics of tropical macroalgal epifauna: patterns and processes in recolonisation of Sargassum fissifolium
}

\author{
Keith Michael Martin-Smith \\ Marine Biology Department, James Cook University of North Queensland, Townsville, Queensland 4811, Australia
}

\begin{abstract}
Aspects of the stability of a community of invertebrate epifauna associated with the large brown alga Sargassum fissifolium were investigated on a fringing, mixed coral/algal reef in Australia. In 2 field experiments $S$. fissifolium plants were defaunated using fresh water and subsequent recolonisation by mobile invertebrates was monitored over time scales of 0 to 6 and 0 to $28 \mathrm{~d}$, together with unmanipulated controls. In both experiments recolonisation was very rapid, with some individuals of most common taxa present within $6 \mathrm{~h}$ of defaunation. Multivariate statistics showed that the system displayed high elasticity and amplitude, re-establishment of epifaunal communities indistinguishable from controls occurring within approximately $2 \mathrm{wk}$. This was against a dynamic background wherein control communities exhibited little short-term variation (within $6 \mathrm{~d}$ ) but showed much greater changes in abundance and composition over a longer time-scale $(28 \mathrm{~d})$. Different taxa generally showed one of 2 distinct recolonisation patterns: (1) 'monotonic' or 'asymptotic' where abundance increased steadily until control levels were attained and (2) 'overshoot' where abundance increased rapidly, peaking at levels significantly higher than control levels before returning to control levels. These data demonstrate that this tropical epifaunal community has the ability to recover rapidly from short-duration, highmagnitude disturbance episodes.
\end{abstract}

KEY WORDS: Stability $\cdot$ Recolonisation $\cdot$ Epifauna

\section{INTRODUCTION}

How stable are natural communities? This question is of fundamental importance in understanding the role of disturbance in structuring communities (Pickett \& White 1985, Karlson \& Hurd 1993). The stability of a system depends upon its resistance to perturbation and its adjustment stability - the amplitude of perturbation from which it can recover and the rate of recovery, usually known as the elasticity of the system (Connell \& Sousa 1983). Highly stable communities can have high resistance to perturbation, high adjustment stability or both. The stability of a community can be evaluated by its response to experimental perturbation (e.g. Smedes \& Hurd 1981, Farrell 1988).

Macroalgae and seagrasses support large populations of mobile invertebrates which may be subject to periodic disturbances of some magnitude, often as a result of bad weather (e.g. Fenwick 1976, Dean \& Connell 1987). However, such communities normally display predictable cycles of abundance (Edgar 1983a, Arrontes \& Anadon 1990, Martin-Smith in press) implying high community stability. Whilst epifaunal populations have been shown to rapidly colonise defaunated substrata (Gunnill 1982, Edgar 1983b, Stoner 1985, Virnstein \& Curran 1986), this has not usually been set against the dynamic background of changes in unmanipulated communities (Smedes \& Hurd 1981, Karlson \& Hurd 1993j. Furthermore, such studies have almost invariably been carried out in northern hemisphere temperate or subtropical areas (but see Stoner 1985) where the frequency and intensity of disturbance may be very different to that in the tropics (Pickett \& White 1985).

Thus, the primary aim of this study was to investigate the elasticity and amplitude of a community of epi- 
fauna in the tropics following a single large perturbation event, i.e. complete defaunation. The system investigated was the community of epifauna inhabiting a species of Sargassum on a fringing reef in Australia. Species of Sargassum are found on fringing reefs in many parts of the world including Hawaii (De Wreede 1976), the Philippines (Ang 1985) and Australia (Price 1989) and may be dominant in terms of cover and/or biomass. These beds are comparable to beds of fucalean or laminarian algae in temperate regions (Gunnill 1982, Edgar 1983a) allowing tropicaltemperate comparisons to be drawn.

A secondary consideration is that although longterm seasonal patterns of variation in abundance of epifauna inhabiting macrophytes have been documented (Nelson et al. 1982, Edgar 1983a, Gunnill 1983, Arrontes \& Anadon 1990), fluctuations in abundance over the time scales of hours to weeks have received little attention. If these chlanges in abundance are of large magnitude then spurious seasonal patterns may be detected or valid phenological data obscured by unpredictable short-term changes. Thus, a necessary prerequisite for the validation of seasonal abundance patterns is an estimate of the magnitude and predictability of changes at smaller spatial scales - hours, days and weeks (Wiens 1989). Monitoring of unmanipulated plants over the course of recolonisation experiments provided data to complement the predictable seasonal changes in abundance and composition of epifauna already documented at Magnetic Island (Martin-Smith in press).

\section{METHODS}

Description of study site. This work was carried out at Geoffrey Bay, Magnetic Island, Queensland, Australia $\left(19^{\circ} 10^{\prime} \mathrm{S}, 146^{\circ} 50^{\prime} \mathrm{E}\right)$. The island, about $7 \mathrm{~km}$ from the mainland, has extensive fringing reefs which support a community of mixed macroalgae and scleractinian corals (Morrissey 1980). The dominant macroalgae are Sargassum spp. which occur in large, mixedspecies stands on hard substrata (coral rubble or moribund areas of living coral). Of the 8 species of Sargassum which occur around the island, 3 are found at the study depth of 3 to $5 \mathrm{~m}$ below mean sea level and the following experiments were performed on only one species, S. fissifolium.

Recolonisation experiments. The short-term dynamics of local populations of mobile epifauna were investigated following experimental defaunation of Sargassum fissifolium. Two experiments were performed Expt 1 was run over a short time scale ( 0 to $6 \mathrm{~d}$ ) and Expt 2 was run over a longer time scale ( 0 to $28 \mathrm{~d}$ ) (for experimental design see Table 1). However the
Table 1. Sampling times and sample sizes for Sargassum fissifolium recolonisation experiments. For each experiment, there were 2 treatments: defaunated (experimental) and control

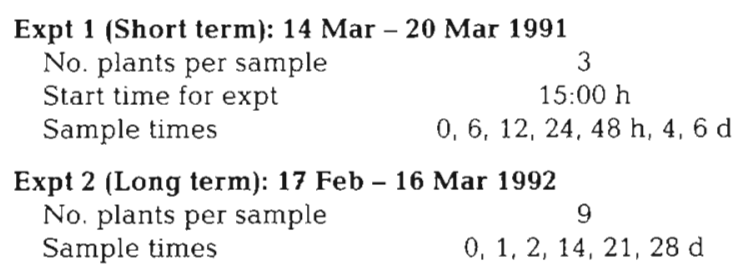

Expt 2 (Long term): 17 Feb - 16 Mar 1992

No. plants per sample 9

Sample times $\quad 0,1,2,14,21,28 \mathrm{~d}$

methodology was the same for both: individual S. fissifolium plants were removed haphazardly from the substratum and placed in buckets of seawater on board the research vessel. Plants were defaunated by two 5 min periods of immersion in fresh water (Gunnill 1982) and were then held in buckets of seawater pending reattachment to the substratum. Six plants were placed in plastic bags for examination in the laboratory to test the efficacy of the defaunation method. For replacement on the substratum, plants were tied on to $40 \times 25 \times 15 \mathrm{~cm}$ plastic mesh baskets near their holdfasts using plastic-coated wire. Six plants were attached to each basket which was then placed in the area from where the plants had initially been taken. At each collection time experimental plants were selected randomly. Unmanipulated control plants were taken haphazardly from the same area at the same time. Times of sampling and number of individuals sampled in both experiments are given in Table 1. Abundance of 5 taxa (gammarid amphipods, total isopods, decapods, polychaetes and gastropods) were enumerated in Expt 1 while abundance of 10 taxa (gammarid and caprellid amphipods, sphaeromatid and other isopods, tanaids, cumaceans, decapods, polychaetes, gastropods and anemones) were enumerated in Expt 2.

Diel changes in epifaunal abundance. The sampling protocol from Expt 1 demanded that 6 and $12 \mathrm{~h} \mathrm{sam}$ ples were taken during darkness (21:00 and 03:00 h, see Table 1). It is known that abundance of some epifaunal organisms can vary markedly between day and night (Livingston 1976, Greening \& Livingston 1982, Edgar 1983b) and this is a potential source of variation in abundance over time. To ascertain the magnitude of this effect samples of epifauna were taken from 9 Sargassum fissifolium plants at 15:00,21:00, 03:00 and 09:00 h on 18-19 March 1991. It is also known that crustaceans from the reef cryptofauna can emerge at night into the water column (Alldredge \& King 1977 , McWilliams et al. 1981, Jacoby \& Greenwood 1988) if these individuals were inadvertently sampled with $S$. fissifolium plants, this could again produce variations in abundance not directly related to the experimental procedure. Emergence traps were used to determine 
the abundance and composition of this fauna. Three tetrahedral plastic emergence traps (see Alldredge \& King 1977), each with a basal area of $0.25 \mathrm{~m}^{-2}$, were deployed on each of the nights of 15 to 17 December 1991 (one over an area of bare substratum, the other two over substratum with attached $S$. fissifolium). The traps were deployed between $16: 30$ and $17: 30 \mathrm{~h}$ and retrieved the next morning between 08:30 and 09:30 h. Three samples of epifauna from $S$. fissifolium were taken concurrently upon retrieval of traps for comparison with the epifauna found in the traps.

Sampling of epifauna. All Sargassum fissifolium plants sampled were of approximately the same size, namely 25 to $35 \mathrm{~cm}$ high and 60 to $120 \mathrm{~g}$ wet wt. Each plant was collected by placing a large plastic bag over it which was held closed while the holdfast was removed from the substratum. The plastic bag had an attached 'cod end' covered with $200 \mu \mathrm{m}$ plankton mesh to allow water to drain out when removed from the sea. Most of the epifauna was removed immediately after sampling by repeated washings of the plant in seawater, the epifauna being retained on the mesh of the cod end. Two further washes of the plant in the laboratory removed any remaining individuals. Epifauna was preserved in $10 \%$ buffered seawater-formalin. The wet weight of each plant was determined after it had been spun in a 'salad spinner' for $60 \mathrm{~s}$ to remove any excess water - this was done in order to standardise numbers of epifauna to unit wet weight of plant.

Analysis of data. Both univariate and multivariate analyses were performed on abundance data from recolonisation experiments. The multivariate abundance data from both experiments were $\log (x+1)$ transformed to homogenise their variances (Hurlburt \& White 1993) and were subsequently analysed using a 2-way MANOVA with treatment (control or defaunated) and time (time since start of experiment) as fixed factors. To examine the patterns at the entire community level a canonical discriminant analysis (CDA) was performed on the data set for each experiment. This procedure allows multivariate data to be visualised in a reduced set of dimensions determined by the perpendicular axes of best fit through the group centroids, standardised to the within-group variances. Univariate plots of untransformed data were used to show the recolonisation patterns of individual taxa and the data for particular time points were tested, where appropriate, with post-hoc sequential Bonferroni tests (Rice 1989). Individual taxon data from the diel sampling procedure were analysed with a 1 -way ANOVA with fixed factor time followed by a post-hoc Student-Newman-Keuls test if a significant result was found. Abundance data from emergence traps from all 3 nights were combined and standardised to 'per plant' values (since emergence traps covered an area containing more than 1 plant).

\section{RESULTS}

The MANOVA for Expt 1 showed significant effects of time, treatment and the interaction between them (Pillai's Trace, $\mathrm{p}<0.001$ ). Thus CDA was used to visualise the processes involved at the community level. Plots of the first 2 canonical axes (representing 74.5 and $10.2 \%$ of the total sample variation) showed clear separation between control and defaunated treatments (Fig. 1A). The greatest variation was shown along
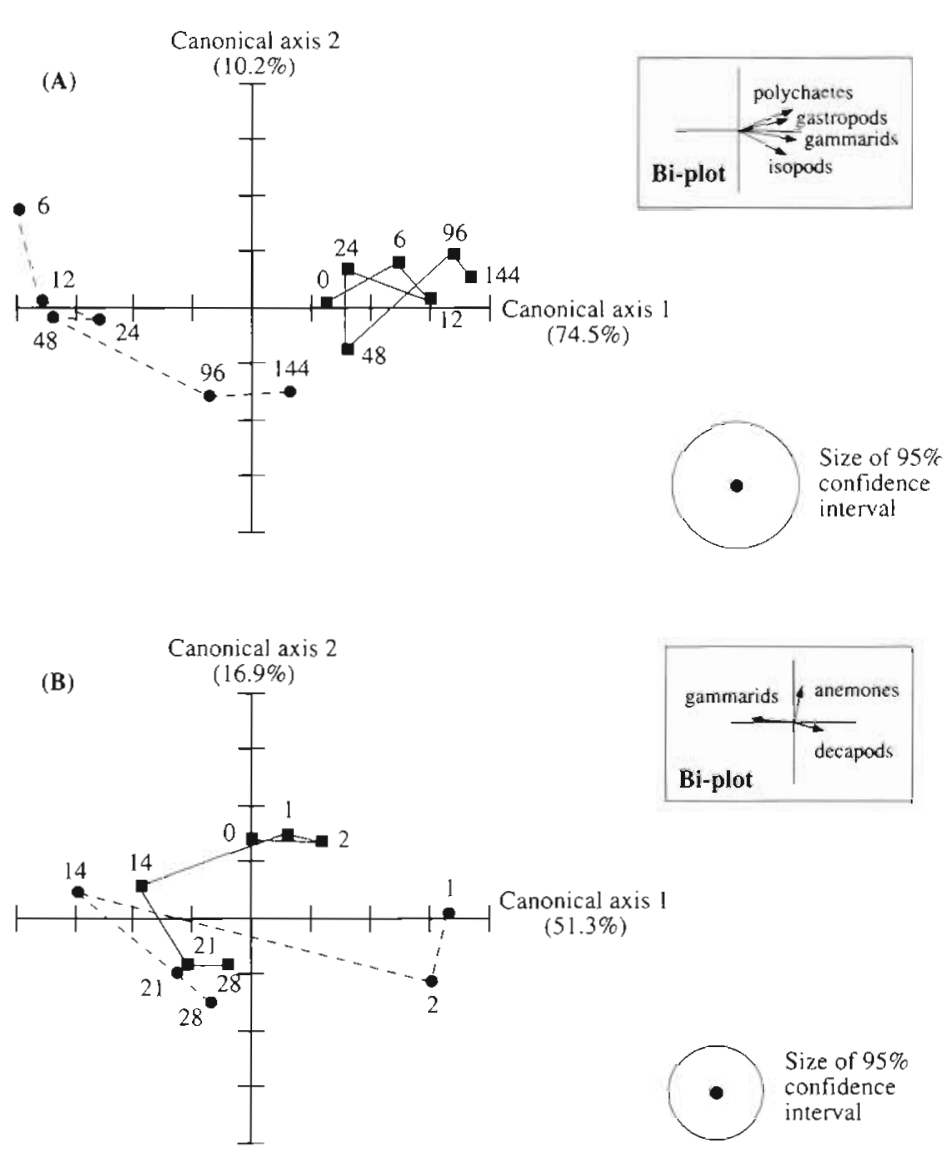

Fig. 1. Canonical discriminant analysis. Plots of first 2 canonical coefficients for epifaunal communities for (A) 0 to $6 \mathrm{~d}$ and (B) 0 to $28 \mathrm{~d}$ experiment. (ロ) Control communities; ( ) experimental communities. Numbers beside points represent sample time in hours from beginning of Expt 1 or days in Expt 2; lines connect points in correct time sequence. Bi-plots show taxa contributing significantly to separation of points. Size of $95 \%$ confidence intervals shown by error circle 


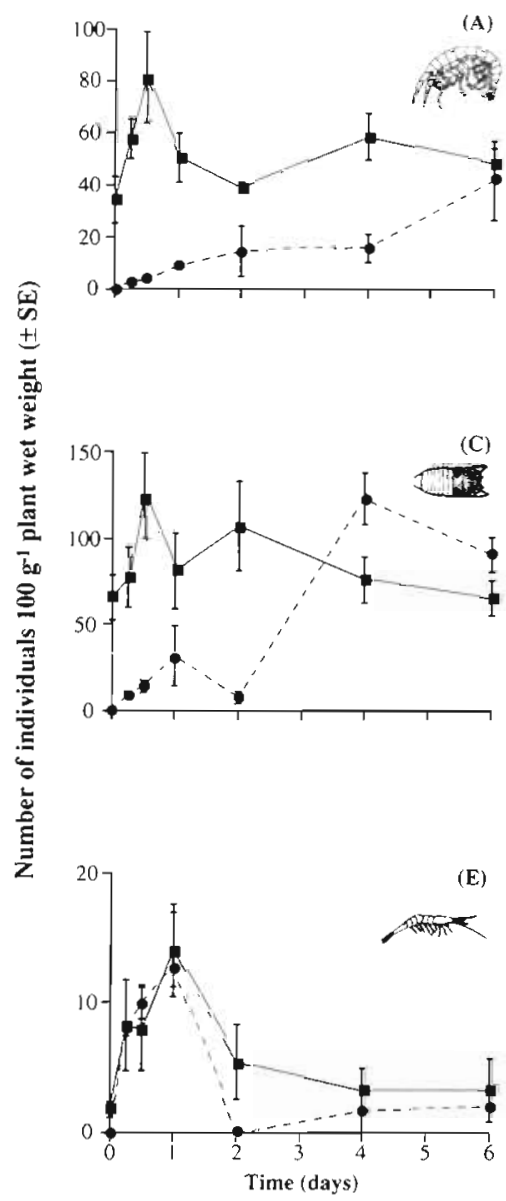

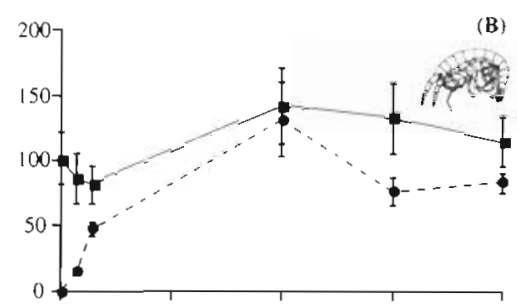
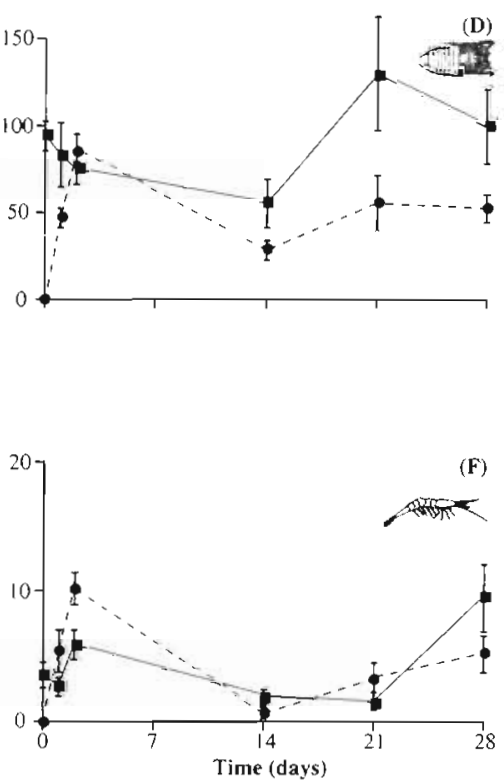

Fig. 2. Abundance of epifauna on control ( $\boldsymbol{\square}$ ) and defaunated (-) Sargassum fissifolium over time. (A) \& (B) gammarid amphipods, (C) \& (D) sphaeromatid isopods, (E) \& (F) decapods. (A), (C) \& (E) from 0 to $6 \mathrm{~d}$ experiment $(n=3)$; (B),

(D) \& (F) from 0 to $28 \mathrm{~d}$ experiment $(\mathrm{n}=9)$

canonical axis 1 , wherein large positive values represented high abundance of gammarids, isopods, polychaetes and gastropods (shown by the bi-plot in Fig. 1A). Control communities were very similar to each other over the $6 \mathrm{~d}$ course of the experiment, the CDA means for each time point clustering closely together, while the defaunated communities showed a directional shift over the course of the experiment along canonical axis 1 as abundance of all taxa increased (Figs. 2 \& 3).

MANOVA of the data from Expt 2 also showed significant effects of time, treatment and their interaction (Pillai's Trace, $p<0.001$ ). Once again, CDA plots of the first 2 canonical variables (representing 51.3 and $16.9 \%$ of total sample variation) showed separation between control and defaunated treatments initially (from 0 to $2 \mathrm{~d}$ ). However, over the longer time scale of this second experiment, these differences became smaller and control and defaunated communities were similar at 14,21 and $28 \mathrm{~d}$ (Fig. 1B). The comparison of the 2 treatments was complicated by the directional movement exhibited by the control communities over the $4 \mathrm{wk}$ of the experiment. Control communities for 0,1 and $2 \mathrm{~d}$ were clustered together but changes in abundance of various taxa led to separation between the 14, 21 and $28 \mathrm{~d}$ communities.

Within the multivariate community response there were at least 2 distinct single species patterns (Figs. 2 to 4). The first type of recolonisation pattern (Type I) was that of steadily increasing abundance from the time of defaunation until control levels were attained - 'asymptotic' or 'monotonic' colonisation. This was shown by gammarids (Fig. 2A, B) and polychaetes (Fig. 3A, B) in both experiments and by sphaeromatids (Fig. 2D), gastropods (Fig. 3D), tanaids (Fig. 4A), cumaceans (Fig. 4C), other isopods (Fig. 4D) and anemones (Fig. 4E) in the second experiment. The second type of pattern (Type II) involved rapid colonisation initially, with abundance of the taxon increasing to significantly higher levels than controls followed by a subsequent decline to control abundance - 'overshoot' colonisation. This response was shown by sphaeromatid isopods in Expt 1 (Fig. 2C) and by decapods (Fig. 2F) and caprellids (Fig. 4B) in Expt 2. Sequential Bonferroni tests showed that abundance for each of these taxa at overshoot was significantly higher than the control value $(\mathrm{p}<0.05)$. High variability in abundance of decapods in Expt 1 (Fig 2E) and gastropods in Expt 2 (Fig. 3D) prevented the designation of these patterns as either Type I or Type II. A summary of the single species colonisation patterns is given in Table 2 .

There were no significant differences in abundance of the 4 most abundant taxa, gammarids, sphaeromatids, polychaetes and gastropods at different times of day (Fig. 5, Table 3). Significantly more cumaceans and decapods were caught at night than during the day and there were greater numbers at 03:00 h than at 21:00 h (Fig. 5, Table 3). Very few individuals of epi- 
EXPERIMENT 1

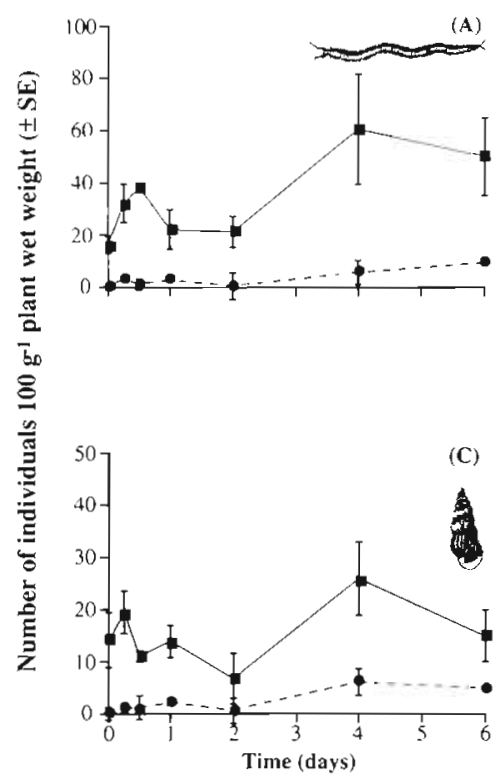

EXPERIMENT 2
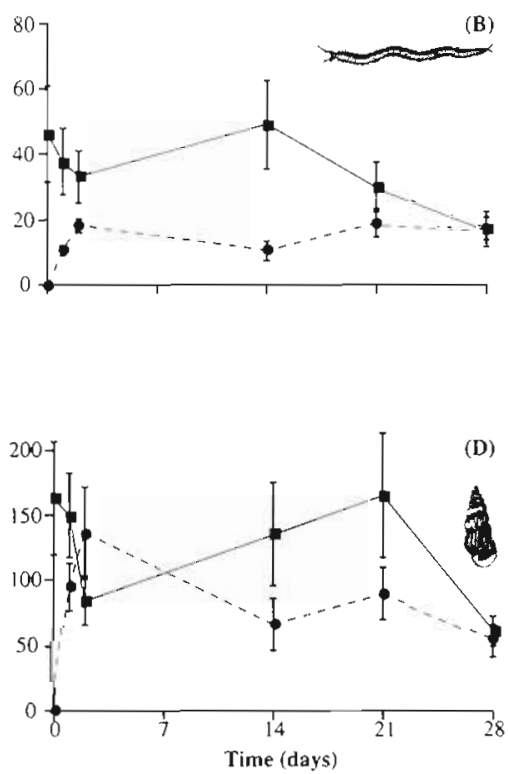

Fig. 3. Abundance of epifauna on control ( $)$ and defaunated (-) Sargassum fissifolium over time. (A) \& (B) polychaetes, (C) \& (D) gastropods. (A) \& (C) from 0 to 6 d experiment $(n=3) ;(B) \&(D)$ from 0 to 28 d experiment $(n=9)$

faunal taxa were captured in emergence traps, the only exception being decapods (Fig. 6). Gammarids and polychaetes were found in emergence traps at approximately 10 to $20 \%$ of their abundance on Sargassum fissifolium plants and there was no significant difference in abundance between traps over $S$. fissifolium or bare substratum. In contrast, abundance of decapods from traps over bare substratum were approximately equal to abundance on $S$. fissifolium and twice this level in traps over substratum with attached $S$. fissifolium.

Table 2. Summary of recolonisation patterns of epifaunal taxa. Type I: abundance increased with time, approached control abundance from below; Type II: abundance increased rapidly above control levels, then declined to control levels

\begin{tabular}{|lc|}
\hline \multicolumn{1}{|c|}{ Taxon } & Type of recolonisation \\
\hline Gammarids & Type I \\
Caprellids & Type II \\
Sphaeromatids & Type I/Type II \\
Other isopods & Type I \\
Tanaids & Type I \\
Cumaceans & Type I \\
Decapods & Uncertain/Type II \\
Polychaetes & Type I \\
Gastropods & Type I/Uncertain \\
Anemones & Type I \\
\hline
\end{tabular}

\section{DISCUSSION}

\section{Community stability}

The community of epifauna living on Sargassum fissifolium at Magnetic Island was clearly highly stable with respect to single, large magnitude perturbations. Rapid recolonisation of individual taxa occurred and measures of total community structure on defaunated plants converged quickly with those on unmanipulated plants. As stated earlier, community stability is determined by the resistance and the adjustment stability of the community to perturbation. The present experiments were only designed to test the adjustment stability of the community. Both components of adjustment stability, amplitude and elasticity, were high in this system. If the amplitude of a system is low, then a major perturbation will result in the formation of a persistent, alternative state (Connell \& Sousa 1983, Paine et al. 1985) - however, in this study the community of epifauna on defaunated plants returned to one indistinguishable from that on unmanipulated plants (Fig. 1). Similarly, if the elasticity of the system is low, then recovery from perturbation will take a long time - communities on defaunated and unmanipulated plants were not significantly different from each other from 2 wk onwards (Fig. 1). The value of measuring changes following perturbation relative to changes in unperturbed communities as urged by Karlson \& Hurd (1993) is clearly demonstrated in the current study. Communities of epifauna on both defaunated

Table 3. ANOVA significance table for epifaunal taxa sampled at 15:00, 21:00, 03:00,09:00 $\mathrm{h}$ on 18-19 March 1991 $n=9$ for each sample. $n s$ : not significant $(p>0.05)$

\begin{tabular}{|c|c|c|}
\hline Taxon & $\begin{array}{l}\text { gnificance of } \\
\text { ampling time }\end{array}$ & $\begin{array}{l}\text { Abundances of epifauna } \\
100 \mathrm{~g}^{-1} \text { in decreasing } \\
\text { order of magnitude }\end{array}$ \\
\hline Gammarids & ns & $\begin{array}{llll}03: 00 & 15: 00 & 21: 00 & 09: 00\end{array}$ \\
\hline Sphaeromatids & ns & $\begin{array}{llll}03: 00 & 15: 00 & 09: 00 & 21: 00\end{array}$ \\
\hline Cumaceans & $p<0.002$ & $03: 00>21: 00>15: 00>09: 00$ \\
\hline Decapods & $p<0.001$ & $03: 00>21: 00>15: 00 \quad 09: 00$ \\
\hline Polychaetes & ns & $\underline{03: 00 \quad 15: 00 \quad 21: 00}$ \\
\hline Gastropods & ns & $\begin{array}{llll}03: 00 & 21: 00 & 15: 00 & 09: 00\end{array}$ \\
\hline \multicolumn{3}{|c|}{$\begin{array}{l}\text { a Bars connect time points which are not significantly } \\
\text { different }\end{array}$} \\
\hline
\end{tabular}




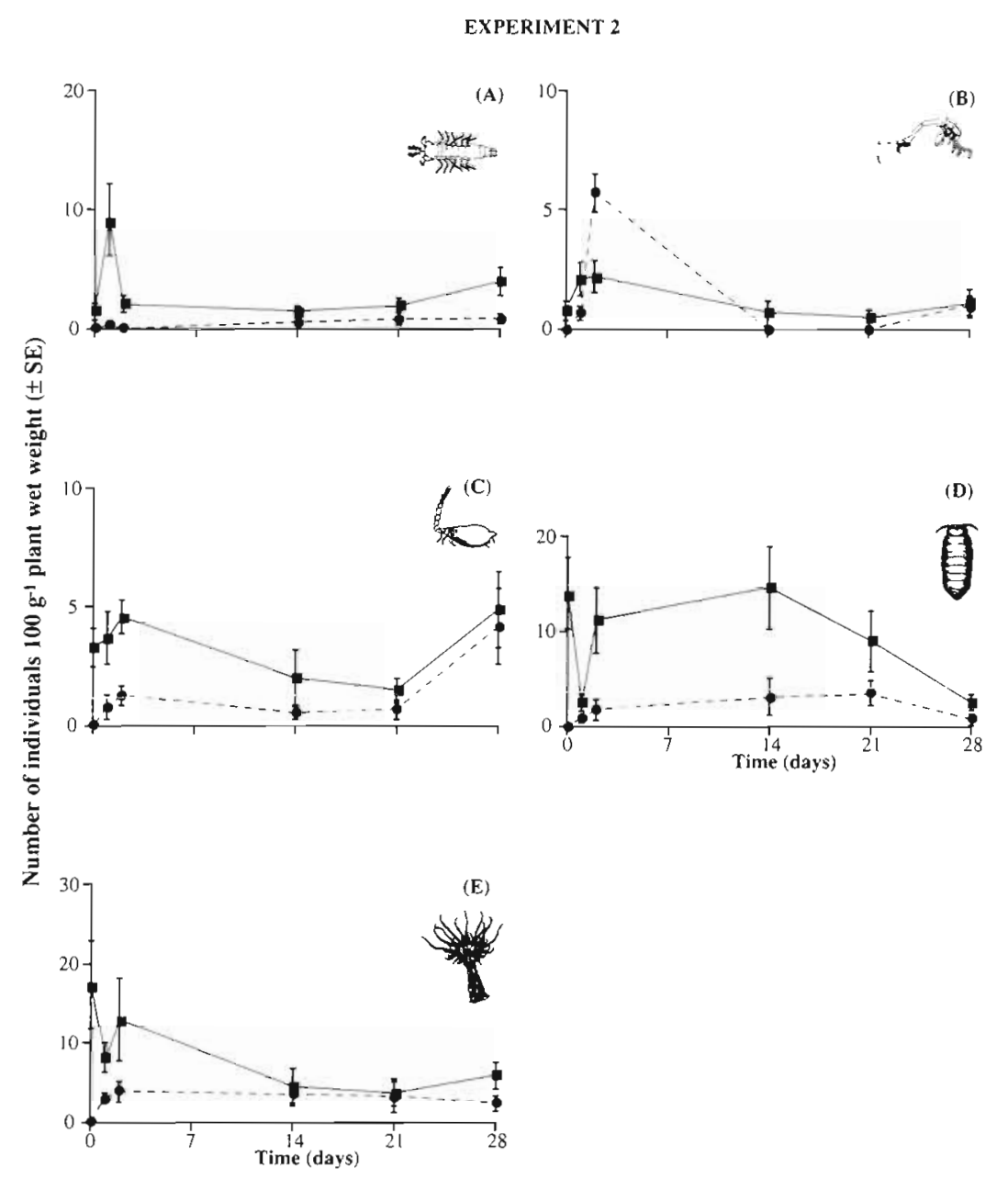

Fig. 4. Abundance of epifauna on control (ם) and defaunated (-) Sargassum fissifolium over time. (A) Tanaids, (B) caprellid amphipods, (C) cumaceans, (D) other isopods, (E) anemones. All samples from 0 to 28 d experiment $(n=9)$ and unmanipulated plants changed significantly between 2 and 4 wk in Expt 2: without comparison between the 2 treatments it would erroneously have been concluded that the community of epifauna on defaunated plants had not fully recovered from perturbation at $2 \mathrm{wk}$.

The ability of tropical epifaunal communities to recover from single, large perturbations may be very important. Tropical areas are characterised by unpredictable high-magnitude disturbance regimes (Hughes 1989). Water movement during tropical storms may remove or defaunate macroalgae while fresh water run-off can be very high in coastal areas following storms. For example, Collins (1978) found salinities as low as $17 \%$ at Magnetic Island following a cyclone and Walker (1981) reported lower salinities during the summer following periods of rainfall, but that minimum values varied widely from year to year. Greater disturbance during the summer months may help to explain epifaunal minima at this time of year (Martin-Smith in press). The rapid recovery of the epifaunal community on Sargassum fissifolium may be a selective product of unpredictable, short duration, high-magnitude disturbance regimes.

Very little manipulative work has been performed on the epifauna of macroalgae in the tropics, the sole comparable study found being that of Stoner (1985). Rates of colonisation were high in Stoner (1985) - 6 species of crustacean were found with abundance of $15 \mathrm{~g}^{-1}$ dry wt on PenicilIus capitatus only $1 \mathrm{~h} 20 \mathrm{~min}$ after defaunation. Colonisation continued rapidly in this experiment, species richness and number of individuals peaking at 3 to $4 \mathrm{~d}$. Unfortunately, the experiment was terminated at Day 4 and no data were collected on background fluctuations on unmanipulated plants. Colonisation of epifauna on temperate macrophytes has also been shown to be rapid - for example, Edgar (1983b) had recolonisation rates of amphipods of 1.7 to $3 \%$ overnight on Sargassum verruculosum and Virnstein \& Curran (1986) found significant numbers of gastropods, amphipods and copepods on artificial seagrass $12 \mathrm{~h}$ after deployment. Howard (1985) used an in situ staining method to look at turnover of crustaceans and gastropods in seagrass beds and found turnover rates of $>50 \%$ in $3 \mathrm{~h}$ for one
Fig. 5. Abundance of epifauna from Sargassum fissifolium sam-

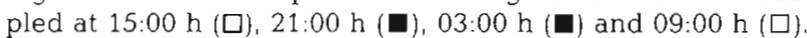
$\mathrm{n}=9$ for all samples 
caridean shrimp, with most taxa he investigated (amphipods, shrimps, gastropods) showing $>25 \%$ turnover in populations in $6 \mathrm{~h}$. Although data are limited, it appears that both tropical and temperate epifaunal communities have high adjustment stability to disturbance but further work is needed to determine causes and mechanisms.

\section{Effects of temporal scale on abundance changes}

In addition to providing information about the stability of the epifaunal community on Sargassum fissifolium, examination of data from unmanipulated plants can be used to assess the effect of temporal scale on the sampling of epifauna. The only way of determining seasonal patterns of abundance is by sampling repeatedly for a period of $2+$ yr. However, this data must be validated by some estimation of the magnitude of temporal variability across the sampling period, in order to separate out the potentially confounding effects of random fluctuations. If seasonal patterns are determined by monthly sampling on a single day, as was the case for epifauna at Magnetic Island (MartinSmith in press), then it is necessary to know the day-today variability in abundance. Wiens (1989) identified this concept and has called for a 'multiscale perspective' to be adopted by ecologists in order to identify patterns and domains within observational data sets.

Data from unmanipulated communities in both recolonisation experiments showed these communities changed little over the temporal scale of hours-days. In Expt 1 all samples taken 96 h or less apart were not sig-

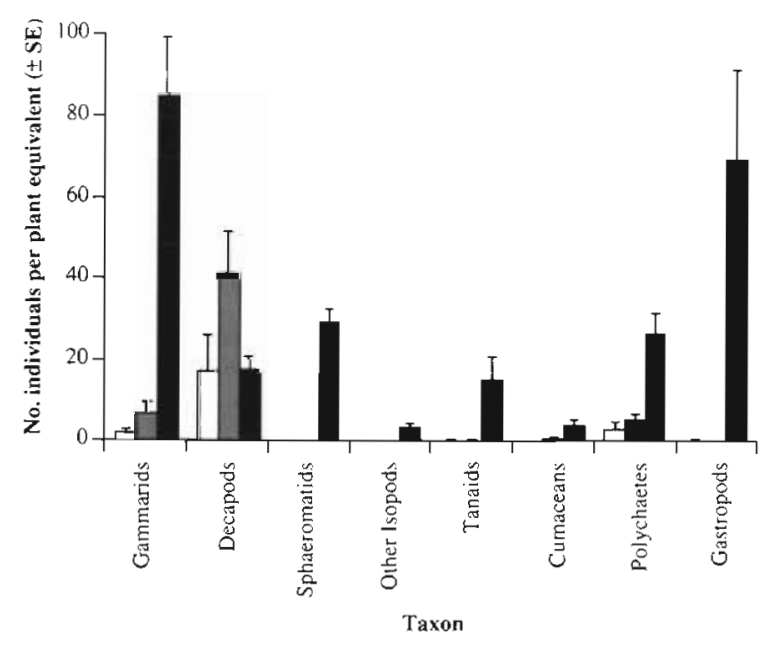

Fig. 6. Abundance of epifauna sampled in emergence traps from 15 to 17 December 1991 (data for all nights combined). Samples from traps over bare substrate ( $\square$ ), traps over substrate and Sargassum fissifolium ( $\mathbf{0}$ ), and from $S$. fissifolium plants (ם). $\mathrm{n}=3,6$, and 9 respectively nificantly different to each other, despite differences in time of day and tide (Fig. 1A). The same pattern was true for Expt 2 - unmanipulated samples at Days 0, 1 and 2 were not significantly different (Fig. 1B). Similarly, samples taken a week apart were not significantly different from each other. However, samples taken 2 wk or more apart showed significant differences in community composition. An implication of these data is as follows: samples taken on a single day accurately reflect the community composition for approximately $2 \mathrm{wk}$ and day-to-day fluctuations in abundance do not significantly impede the detection of seasonal patterns. It is interesting that the temporal scale of detectable difference between unmanipulated communities is approximately the same as the elasticity of the community.

Diel population movements also have the potential to affect pattern detection in epifaunal populations. Synchronous diel population movements have been observed for a numerous taxa inhabiting a wide variety of substrata. Reef associated zooplankton are commonly observed to move into the water column at night (e.g. Alldredge \& King 1977, McWilliams et al. 1981, Jacoby \& Greenwood 1988) and macrofauna associated with seagrass beds are predictably more abundant at night (Livingston 1976, Greening \& Livingston 1982). Edgar (1983b) found that populations of amphipods on Zonaria turneriana decreased at night, but that populations on Sargassum verruculosum did not change predictably over a $24 \mathrm{~h}$ period, while Fincham (1974) found that $80 \%$ of amphipods in a light trap were epifaunal species. Conversely Ledoyer (1969) and Montouchet (1979) found increased abundance of populations of epifauna at night due to immigration by benthic species. In the present work changes in most abundant taxa were not significant or predictable between day and night (Fig. 5), nor did significant numbers of individuals emerge from the substrata on to S. fissifolium (Fig. 6). The only exceptions to this general pattern were cumaceans and decapods. Decapods left both the $S$. fissifolium and the substratum at night, consequently their abundance may have been underestimated in the 6 and $12 \mathrm{~h}$ samples in Expt 1. However, if emergence was not density dependent then this would not have altered the relative difference between control and experiment plants. Overall it appears that diel changes in abundance were of similar magnitude and importance as day-to-day changes.

\section{Patterns of recolonisation}

Epifauna colonised in 2 ways - the asymptotic Type I pattern and the overshoot Type II pattern (Table 2) - and it is interesting to speculate on the 
processes underlying these patterns. Sphaeromatid isopods, caprellids amphipods and decapods (mostly shrimps) colonised at much faster rates than other taxa. Are there any common features among these taxa which would provide an explanation for this? One obvious explanation would be a difference in locomotory abilities between the taxa. Although sphaeromatids, decapods and caprellids have well-developed swimming behaviours (Barnes 1980, Krapp-Schickel 1993), so do gammarids and polychaetes (Barnes 1980) which do not colonise as rapidly. Thus, it seems that locomotory differences were not completely responsible for the 2 types of colonisation patterns.

An alternative hypothesis is that behaviour was different between the taxa with the rapidly colonising taxa having greater turnover rates among plants. 'Investigation' of new habitats (i.e. periodic immigration and emigration behaviour) could be more pronourced in sphaeromatids, capreliids and decapods, resulting in the faster location of unoccupied habitats. If epifauna actively searched for suitable habitats, different taxa may have used different cues for locating habitats. A defaunated plant initially may have lacked a specific cue for slow-colonising taxa, or produced a specific cue for fast-colonising taxa. It has been shown that sphaeromatid isopods exhibit aggregative settling behaviour (Holdich 1976, Shuster 1992) and this may have been the reason for their rapid colonisation. Further experimentation will be needed to differentiate between these hypotheses.

Acknowledgements. I thank my supervisors, Dr Geoff Jones and Prof. Howard Choat, and the numerous field assistants who helped collect the data, especially Ben Stobart and Ilona Stobutzki. For statistical advice Natalie Moltschaniwskyj has been invaluable and the manuscript has benefited greatly from the criticisms of Ben Stobart, Jo Pitt and 3 anonymous reviewers. This work has been part of a Ph.D. funded by a CFSP scholarship.

\section{LITERATURE CITED}

Alldredge, A. L., King, J. M. (1977). Distribution, abundance and substrate preferences of demersal reef zooplankton at Lizard Island Lagoon, Great Barrier Reef. Mar. Biol. 41. $317-333$

Ang, P. O. (1985). Phenology of Sargassum siliquosum J. Ag. and S. paniculatum J. Ag. (Sargassaceae, Phaeophyta) in the reef flat of Balibago (Calatagan, Philippines). Proc. 5th int. coral Reef Congr., Tahiti 5: 51-57

Arrontes, J., Anadon, R. (1990). Seasonal variation and population dynamics of isopods inhabiting intertidal macroalgae. Scient mar. 54: 231-240

Barnes. R. D. (1980). Invertebrate zoology. Saunders College, Philadelphia

Collins, J. D. (1978). A study of the interactive biology of corals. Ph.D. thesis, James Cook University of North Queensland, Townsville

Connell, J. H., Sousa, W. P. (1983). On the evidence needed to judge ecological stability or persistence. Am. Nat. 121 $789-824$

Dean, R. L., Connell, J. H. (1987). Marine invertebrates in an algal succession. III. Mechanisms linking habitat complexity with diversity. J. exp. mar. Biol. Ecol. 109: 249-273

De Wreede, R. E. (1976). The phenology of three species of Sargassum (Sargassaceae, Phaeophyta) in Hawaii. Phycologia 15: 175-183

Edgar, G. J. (1983a). The ecology of south-east Tasmanian phytal animal communities. II. Seasonal change in plant and animal populations. J. exp. mar. Biol. Ecol. 70 $159-179$

Edgar, G. J. (1983b). The ecology of south-east Tasmanian phytal animal communities. IV. Factors affecting the distribution of amphithoid amphipods among algae. J. exp. mar. Biol. Ecol. 70: 205-225

Farrell, T. M. (1988). Community stability: effects of limpet removal and reintroduction in a rocky intertidal community. Oecologia 75: 190-197

Fenwick, G. D. (1976). The effect of wave exposure on the amphipod fauna of the alga Caulerpa brownii. J. exp. mar. Biol. Ecol. 25: 1-18

Fincham, A. A. (1974). Periodic swimming behaviour of amphipods in Wellington Harbour. N.Z. J. mar. Freshwat. Res. 8: 505-521

Greening, H. S., Livingston, R. J. (1982). Diel variation in the structure of seagrass-associated epibenthic macroinvertebrate communities. Mar. Ecol. Prog. Ser. 7: 147-156

Gunnill, F. C. (1982). Effects of plant size and distribution on the numbers of invertebrate species and individuals inhabiting the brown alga Pelvetia fastigiata. Mar. Biol. 69: $263-280$

Gunnill, F. C. (1983). Seasonal variations in the invertebrate faunas of Pelvetia fastigiata (Fucaceae): effects of plant size and distribution. Mar. Biol. 73: 115-130

Holdich, D. M. (1976). A comparison of the ecology and life cycles of two species of littoral isopod. $J$. exp. mar. Biol. Ecol. 24: 133-149

Howard, R. K. (1985). Measurements of short-term turnover of epifauna within seagrass beds using an in situ staining method. Mar. Ecol. Prog. Ser. 22: 163-168

Hughes, T. P. (1989). Community structure and diversity of coral reefs: the role of history. Ecology 70: 275-279

Hurlburt, S. H., White, M. D. (1993). Experiments with freshwater zooplanktivores: quality of statistical analyses. Bull. mar. sci. 53: 128-153

Jacoby, C. A., Greenwood, J. G. (1988). Spatial, temporal, and behavioural patterns in the emergence of zooplankton in the lagoon of Heron Reef, Great Barrier Reef Mar. Biol. 97: $309-328$

Karlson, R. H., Hurd, L. E. (1993). Disturbance, coral reef communities, and changing ecological paradigms. Coral Reefs 12: $117-125$

Krapp-Schickel, G. (1993). Do algal-dwelling amphipods react to the 'critical zones' of a coastal slope? J. nat. Hist. 27: $883-900$

Ledoyer, M. (1969). Ecologie de la faune vagile des biotopes Méditerranéens accessible en scaphandre autonome. V. Étude des phénomènes nycthéméraux. Les variations nycthemérales des populations animales dans les biotopes. Téthys 1: 291-308

Livingston, R. J. (1976). Diurnal and seasonal fluctuations of organisms in a north Florida estuary. Estuar. coast mar. Sci. $4: 373-400$

Martin-Smith, K. M. (in press). Seasonal variation in tropical benthic Sargassum and associated motile epifauna. Proc. 7 th int. Coral Reef Symp 
McWilliams, P. S., Sale, P. F., Anderson, D. T (1981). Seasonal changes in resident zooplankton sampled by emergence traps in One Tree Lagoon, Great Barrier Reef. J. exp. mar. Biol. Ecol. 52: 185-203

Montouchet, P. C. G. (1979). Sur la communauté des animaux vagile associés à Sargassum cymosum C. Agardh, à Ubatuba, État de São Paulo, Brésil. Stud. Neotrop. Fauna 14: $33-64$

Morrissey, J. (1980), Community structure and zonation of macroalgae and hermatypic corals on a fringing reef flat of Magnetic Island (Queensland, Australia). Aquat. Bot. 8: $91-139$

Nelson, W. G., Cairns, K. D., Virnstein, R. W. (1982). Seasonality and spatial patterns of seagrass-associated amphipods of the Indian River lagoon, Florida. Bull. mar. Sci. 32: 121-129

Paine, R. T., Castilla, J. C., Cancino, J (1985). Perturbation and recovery patterms in starfish dominated intertidal assemblages in Chile, New Zealand and Washington State. Am. Nat. 125:679-691

Pickett, S. T A., White, P. S. (eds.) (1985). The ecology of natural disturbance and patch dynamics. Academic Press, Orlando

This article was presented by R. H. Karlson (Senior Editorial Advisor), Newark, Delaware, USA
Price, I. R. (1989). Seaweed phenology in a tropical Australian locality (Townsville, North Queensland). Botanica mar. 32 $399-406$

Rice, W. R. (1989). Analyzing tables of statistical tests. Evolution 43: 223-225

Shuster, S. M. (1992). The use of artificial sponges as breeding habitat by Paracerceis sculpta (Holmes) (Crustacea: Isopoda). J exp. mar. Biol. Ecol. 165: 75-89

Smedes, G. W., Hurd, L. E. (1981). An empirical test of community stability: resistance of a fouling community to a biological patch-forming disturbance. Ecology 62: $1561-1572$

Stoner, A. W. (1985). Penicillus capitatus: an algal island for macrocrustaceans. Mar. Ecol. Prog. Ser. 26: 279-287

Virnstein, R. W., Curran, M. C. (1986). Colonization of artificial seagrass versus time and distance from source. Mar. Ecol. Prog. Ser. 29: 279-288

Walker, T. A. (1981). Seasonal salinity variations in Cleveland Bay, Northern Queensland. Aust. J. mar. Freshwat. Res. 32: $143-149$

Wiens, J. A. (1989). Spatial scaling in ecology. Func. Ecol. 3 385-397

Manuscript first received: November 23, 1993

Revised version accepted: April 6, 1994 